\title{
Asset Market Linkages in a Regime Switching Environment: Evidence from Commodity and Stock Markets in India
}

\author{
Shelly Singhal ${ }^{\mathrm{a}}$ \\ P. C. Biswal ${ }^{b}$
}

\begin{abstract}
Time series models investigating the linkages between various asset markets (Commodity and Equity) in India have assumed a symmetric and linear relationship between them. They examine these interrelationships by assuming the presence of a uniform economic state. However the returns from commodity futures and stock market do not show a continuous trend but exhibit time varying behaviour i.e. the returns of stocks might be higher in a certain economic condition and it may fall as the economic environment changes due to financial crises, oil price rise, rupee depreciation etc. Similarly the return of commodities is also subject to variation with the changing economic conditions due to which the basic assumptions of stationary and linearity of time series models gets refuted. Therefore, this paper empirically examines the interrelationships between commodity futures (Energy, Metal and Agriculture) and stock markets in dynamic economic states by employing Markov Regime Switching model proposed by Hamilton (2005) which has the capability of capturing temporal asymmetries and nonlinear dynamics of time series. For each market a composite index indicating the overall movement and performance of a particular investment asset has been considered. In order to provide robust results this paper uses daily data from 2006 to 2014 which significantly represents different states in the Indian Economy. The result of the study confirms the impact of economic environment on Indian commodity and stock markets and validates the presence of two distinct regimes: a "tranquil regime" representing the state of economic expansion and a "crisis regime" representing the state of economic decline. Additionally, the result confirms that commodities and stock markets oscillate between high and low volatility regimes and this movement is different across different commodity class (Energy, Metal and Agriculture). In a portfolio, when commodity futures are combined with stock, due consideration must be given to the state varying behaviour of different asset class. However, previous studies on performance of commodity futures in context of portfolio have been done in a single time period/static context and therefore the results of the study provide interesting insights for investors and portfolio managers. By detecting the switching points in the economic states, they can rebalance their portfolio accordingly so as to reduce loss and enhance portfolio returns.
\end{abstract}

Keywords: Commodity Market, Markov Regime Switching Model, Portfolio Management, Stock Market

JEL Classification: G10, G11,C6, E30

aDoctoral Scholar, Finance, Management Development Institute, Gurgaon, India, fpm13shelly_s@mdi.ac.in

bProf. Dr., Finance, Management Development Institute, Gurgaon, India, pcbiswal@mdi.ac.in 


\section{Introduction}

Commodities have emerged as a significant mode of alternative investment today all over the world. While they have been in existence in many of the developed markets, commodities, in Indian context have seen a brisk growth in the last few years, which is quite visible in the volumes of contracts traded. Majority of the Literature on Indian commodity markets has focused on the issue of market efficiency, price volatility, price discovery, market integration, Contango and Normal backwardation and a number of studies have been done in this context. These markets were found to be efficient and doing well on price discovery Ahuja (2006); Bose(2008); Karande (2006); Sahi \& Raizada (2006); Nath \& Lingareddy (2008) ,Brajesh Kumar(2009); Srinivasan (2012) but relatively poorly on hedging effectiveness (Bose (2009); Kumar (2010); Yaganti and Kamaiah 2012);Gupta \& Singh(2007); Aggarwal N, Jain S, Thomas S (2014). During the crises of 2008, when the stock markets were performing badly and the SENSEX was giving a return of $0.7 \%$, agricultural and metal indices of MCX were providing returns to the extent of $18 \%$ and $17 \%$ respectively. It was during that time commodity markets attracted the attention of the Indian investors and garnered an image of a separate asset class that provided diversification benefits. Thus, it becomes imperative to delve deep into commodities and investigate its linkages with other asset classes in the Indian Context.

In context of developed commodity markets, a number of researchers have confirmed that commodity prices tends to move in opposite direction with equity markets and exhibit zero or very low correlation with them Bodie \& Rosansky(1980); Edwards \& Park (1996); Lee,Leuthold. \& Cordier(1986) ; Schneeweis and Spurgin (2000); Jensen et al. (2002) ;Henry G. Jarecki 2007); Anson \& Mark (1999) Jensen, Johnson \& Mercer,(2009); McCown and Zimmerman (2006);Gorton \& Rouwenhorst(2006); Jalil, Ghani, Daud, \& Ibrahim (2009); Park \& Ratti, (2008); Wang, Wang, \& Huan (2010). In addition, several researchers have also confirmed that returns for commodities show positive correlation with unexpected inflation and exhibit better performance under high inflation times Greer (1978); Bodie (1983); Halpern and Warsager (1998); and Gorton, Hayashi \& Rouwenhorst (2007). However, in Indian context, this concept of the comovement of Commodity and equity markets remains relatively unexplored. The only studies in this context was done by Mishra (2008) and Brajesh kumar (2008) who investigated the portfolio performance of Indian commodity markets and found favourable results in context of diversification benefits of commodities.

One of the major drawbacks of the aforementioned studies is that they have assumed a symmetric and linear relationship between commodity and equity markets and examined their co-movement solely on the basis of correlation. These studies assume the presence of uniform economic state throughout the duration of the study. Researches done by Hui-Ming Zhu, Keming Yu (2012); Hsiang-Tai Lee(2010); Ramaprasad \& Shawkat (2011) ; Levy\& Kaplanski (2015) confirmed that the returns from commodity futures and stock market do not show a continuous trend but exhibit time varying behaviour i.e. the returns of stocks might be higher in certain economic conditions while it may fall as the economic environment changes due to financial crises, oil price rise, rupee depreciation etc. Similarly the returns from commodities is also subject to variation with changes in economic conditions Wai Mun Fong, Kim Hock See (2002); Minh T. (2009); Nikos \& Panos (2011); Kuang-Liang Chang (2012) ; Shiu-Sheng Chen (2010); Lin \& Wesseh (2013) ; Gargano,, Pettenuzzo, \& Timmermann (2014) due to which the basic assumptions of stationary and linearity of time series models gets refuted.

Although in context of developed commodity markets, recently a number of researchers has ve pointed out that correlations between commodity and other asset classes is time varying and different in bearish and bullish markets, restrictive and expansive monetary policy, pre and post crises, time varying interest rates Jensen et al. (2000); Cheung \& Miu (2010) ; Choi \& Hammoudeh (2010) ; Qiang Ji, Ying Fan (2012) ; Jing-zhi Huang \& Zhong (2013) and Delatte and Lopez (2013).

The above mentioned linkages between equity and commodities have been established using a number of approaches. Each comes with its own merits and demerits. The magnum opus by Hamilton Hamilton(1989) suggests strongly that regime switching governs the distribution of returns on an asset. Multivariate Markov switching model has been helpful in analysing nexus between stock and commodity markets Julien Chevallier (2012) and presence of regimes in commodity sectors in India Shalini and Krishna 
(2015). A Multivariate MSIAH model has been used by Chan, Treepongkaruna, Brooks and Gray (2010) to explore the asset market linkages between five assets - US Stock, T Bonds, Oil, Gold and Real Estate across three asset classes under two regimes - tranquil and crisis while a Multivariate Markov switching model is used to study the impact of US house mortgages on equity and commodities Julien Chevallier (2012). The study produced significant results by establishing correlations that could prove useful for an investor seeking diversification benefits from varied asset classes. Correlations and volatility spill overs have also been studied for commodity (gold and oil) and stock market (S\&P 500 index) using Vector Autoregression VAR GARCH model in the American context. The relationship between Asian Equity markets and commodity futures market has been analysed using Bivariate BEKK GARCH model Thuraisamy, Sharma and Ahmed (2013). A seminal study Hammoudeh et. Al. (2014) depicting the dependence of commodity and stock markets in China that produced some phenomenal results has its foundation using Copula Functions for analysis. While these standard models of analysis provide significant results, another method has been proposed by Svetlana Boyarchenko and Levendorskii (2007) that incorporates regime switching due to policy interventions and provides significantly accurate results for regimes greater than two in number. A Hidden Markov model has been used to analyse relationship between correlation and volatility for exchange rates, S\&P 500 index and commodities Charlot and Marimoutou (2014).

While most of these studies that allude to significant linkages between stock and commodity markets have been performed at a global level, they mostly encompass stable and large economies like USA and China. Little study has been conducted over the established Indian equity market and the nascent yet growing Indian commodity market. Shalini and Krishna (2015) pPresent a study that investigates the impact of financial crisis on Indian commodity markets (18 commodities) and provide evidence for the existence of two regimes in all commodity sectors and switch in regime from low volatility to high volatility using Markov Regime Switching model. However, there is no single study in Indian literature that considers the direct impact of time varying economic states on the co-movements of Indian commodity and equity markets. Therefore, this paper attempts to fill this gap by empirically examining the interrelationships between commodity futures (Energy, Metal and Agriculture) and stock markets in changing economic states. The present study adds to the current literature by providing fresh insights on the co-movement of equity and stock markets in a dynamic environment in context of India. The findings of the study will be important for investors, portfolio managers and policymakers from the point of view of portfolio diversification, hedging and better risk management practices.

\section{Empirical Modelling}

For analysis of co-movements and interaction of different asset classes across time varying economic states, Markov Regime Switching model proposed by Hamilton (1986) is the dominant model used by various researchers. However in the present study the regime switching mean and heteorskedasticity model proposed by Kin (1999) has been used. This model has the capability of capturing temporal asymmetries and nonlinear dynamics of error term in addition to the mean return. The major advantage of Regime Switching model is that there is no need to explicitly specify when the shift in economic states occurs. It simply relies on the data to detect the switching point in the volatility states of the returns, calculates the transition probability of moving from one state to another state and measure lengths of duration in each state. Once the switching points were detected, the interrelationship among various asset markets has been examined.

Consider a univariate autoregressive process in which $S_{t}$ represents the particular regime prevailing at a point of time. In this model the switching mechanism is controlled by an unobservable state mechanism which follows the first order Markov chain and the current value of the state $S_{t}$ depends only on the immediate past value i.e. St-1. The following equations describe the Markov-switching in mean and error term so that regime specific mean returns and standard deviation can be obtained.

$$
\left[R_{S t}\right]=\left[\mu_{S t}\right]+[\beta]\left[R_{t-1}\right]+\left[e_{S t}\right]
$$

Where $e_{t} \mid S_{t} \sim i i d \quad N\left(0, \sigma_{S t}^{2}\right)$

$\sigma_{S t}^{2}=\sigma_{0}^{2}\left(1-S_{t}\right)+\sigma_{1}^{2} S_{t}, \quad \sigma_{0}^{2}<\sigma_{1}^{2}$ 
Where $R_{S t}$ is the rate of return of a commodity price or the CNX NIFTY or G-Sec index, $\mu_{S t}$ is the regime specific intercept term, $\beta$ is the regime independent auto regressive coefficient, $\sigma_{0}^{2}$ and $\sigma_{1}^{2}$ refer to the low and high volatilities and $S_{t}$ is a latent state-dependent parameter and follows an irreducible ergodic $M$-state Markov process with transition probabilities given by

$$
\begin{aligned}
& P\left[S_{t}=0 \text { given } S_{t-1}=0\right]=q \\
& P\left[S_{t}=1 \text { given } S_{t-1}=1\right]=p
\end{aligned}
$$

Where $S_{t}=0$ refers to low volatility regime at time $t$ while $S_{t}=1$ refers to high volatility regime at time $t$ with $p$ and $q$ being the transition probabilities. Let the expected duration of low volatility regime $\sigma_{0}$ be $E\left(S_{t}=0\right)$ and that of high volatility regime $\sigma_{1}$ be $\left.S=1\right)$, then

$$
\begin{aligned}
& E\left(S_{t}=0\right)=\frac{1}{1-q} \\
& E\left(S_{t}=1\right)=\frac{1}{1-p} \\
& f\left(r_{t}, S_{t}, S_{t-1} \mid I_{t-1}\right)=f\left(r_{t} \mid S_{t}, S_{t-1}, I_{t-1}\right) \times P\left[S_{t}, S_{t-1} \mid I_{t-1}\right] \\
& =\frac{1}{\sqrt{2 \pi \sigma_{S_{t}}^{2}}} e^{\left[-\frac{e_{t}^{2}}{2 \sigma_{D_{t}}^{2}}\right]} \times P\left[S_{t}, S_{t-1} \mid I_{t-1}\right] \\
& \text { Where } e_{s t}^{2}=\left(r_{s t}-\mu_{s t}-\emptyset_{s t} r_{t-1}\right)^{2}
\end{aligned}
$$

This can be then used to derive the marginal density function $f\left(r_{t} \mid I_{t-1}\right)=\sum_{S_{t}=0}^{1} \sum_{S_{t-1=0}}^{1} f\left(r_{t}, S_{t}, S_{t-1} \mid I_{t-1}\right)$

$$
=\sum_{S_{t}=0}^{1} \sum_{S_{t-1=0}}^{1} f\left(r_{t} \mid S_{t}, S_{t-1}, I_{t-1}\right) \times P\left[S_{t}, S_{t-1} \mid I_{t-1}\right]
$$

Next computing the logarithmic likelihood as:

$$
\ln L=\sum_{t=1}^{T} \ln \left[\sum_{D_{t}=0}^{1} \sum_{D_{t-1=0}}^{1} f\left(r_{t} \mid D_{t}, D_{t-1}, I_{t-1}\right) \times P\left[D_{t}, D_{t-1} \mid I_{t-1}\right]\right]
$$

Where probability $P\left[S_{t}=j, S_{t-1}=i \mid I_{t-1}\right]=P\left[S_{t}=j \mid S_{t-1}=i\right] \times P\left[S_{t-1}=i \mid I_{t-1}\right]$ for $\mathrm{i}, \mathrm{j}=0,1$

Next the weight term $P\left[S_{t}, S_{t-1} \mid I_{t-1}\right]$ can be computed as follows once $r_{t}$ is observed at time $t$.

$$
P\left[S_{t}=j, S_{t-1}=i \mid I_{t}\right]=\frac{f\left(r_{t} \mid S_{t}=j, S_{t-1}=i, I_{t-1}\right) \times P\left[S_{t}=j, S_{t-1}=i \mid I_{t-1}\right]}{\sum_{S t=0}^{1} \sum_{S_{t-1=0}}^{1} f\left(r_{t} \mid S_{t}=j, S_{t-1}=i, I_{t-1}\right) \times P\left[S_{t}=j, S_{t-1}=i \mid I_{t-1}\right]}
$$

With $P\left[S_{t}=j \mid I_{t}\right]=\sum_{S_{t-1}=1}^{1} P\left[S_{t}=j, S_{t-1}=i \mid I_{t}\right]$

The appropriate weights can be achieved by iterating equations for $t=1,2, \ldots ., T$. In the present study the algorithm suggested by Kim (1996) has been used to calculate the smoothed probability in each regime.

\section{Data and Preliminary Analysis}

In order to investigate the interrelations between stock and commodity market in India across time varying economic states, this study uses daily closing prices for commodity and stock indices. The main focus of the study will be on overall investment performance of various asset classes not the individual security/component of the asset class. Therefore, for each investment asset class a composite index indicating the overall movement and performance of a particular investment asset has been considered. For Equity market returns CNX NIFTY Index of National Stock Exchange (NSE) and for bond return NSE Government Securities Index has been considered as a proxy. CNX NIFTY is a free float market capitalisation based index that represents the movement of stocks of the 50 most financially sound and actively traded firms. These 50 stocks belong to the 23 different sectors of the economy and therefore indicate the average movement of equity markets. The NSE Government Securities Index is a market capitalization based index of all outstanding sovereign securities - Treasury Bills and Dated Government Securities. It reflects the gain/loss on a sovereign securities portfolio on account of movement/change in interest rates. In context of Indian commodity markets, Multi Commodity Exchange (MCX) is India's first listed commodity futures exchange 
which has the highest market share of nearly $81 \%$ of the total commodities markets and it has a number of passive commodity indexes which are fully investible. In the present study three different sectors of commodity market namely agriculture, energy and metal have been considered. For agriculture sector MCX AGRI, for energy sector MCX ENERGY and for metal sector MCX METAL index has been taken as a proxy. The data span of the study ranges from 2006 to 2014 which was procured from National Stock Exchange and Multi Commodity Exchange India websites. The study period was selected on the basis of data availability and additionally this time frame represents booming, recessionary as well as recovering Indian economy. Table 1 reports the descriptive statistics for various asset market index returns.

Table 1. Descriptive statistics for asset market index returns

\begin{tabular}{lccccc}
\hline Parameter & DLA & DLE & DLG & DLM & DLN \\
\hline Mean (\%) & 0.0179 & $-8.80 \mathrm{E}-06$ & 0.0200 & 0.0335 & 0.0477 \\
Median (\%) & $3.71 \mathrm{E}-06$ & 0.0363 & 0.0227 & 0.0861 & 0.0880 \\
Maximum (\%) & 14.4689 & 11.3116 & 5.2846 & 6.6337 & 16.3343 \\
Minimum (\%) & -21.4791 & -8.7303 & -6.9228 & -13.0525 & -13.0142 \\
Std. Dev. (\%) & 1.2225 & 1.6534 & 0.8778 & 1.2403 & 1.5407 \\
Skewness & -3.881503 & -0.165828 & -0.106326 & -1.389811 & 0.018405 \\
Kurtosis & 100.6810 & 6.721302 & 10.40937 & 15.76152 & 12.92155 \\
Jarque-Bera & 954582.8 & 1387.666 & 5462.354 & 16958.77 & 9786.436 \\
Probability & 0.000000 & 0.000000 & 0.000000 & 0.000000 & 0.000000 \\
ADF Test (Price) & -1.552935 & -1.148059 & -2.274035 & -1.569215 & -1.842833 \\
p-value & 0.8110 & 0.9193 & 0.4475 & 0.8049 & 0.6835 \\
ADF Test & -45.78131 & -46.68740 & -29.18221 & -50.42759 & -44.97935 \\
(Returns) & & & & & \\
p-value & 0.0001 & 0.0001 & 0.0000 & 0.0001 & 0.0001 \\
\hline
\end{tabular}

Notes: The sample period ranges from Jan 2006 to Dec 2014. The statistics are for the first differences of the log of the variables on a daily basis.

Fig. 1 plots the daily prices for each of the five assets under consideration from 2006 to 2015.

Time series plots clearly indicate that movement of price index varies greatly over time. From late 2007 to early 2008, when the price of Nifty showed a significant decline, crude oil prices reached their peak. On the similar lines from early 2008 till 2009 when the Nifty prices were low, prices of Government Security Index and Metal Index rose significantly. In 2011, when the Agriculture Index was at its highest level, prices of Nifty were plummeting downwards albeit relatively, however in 2013, when there was a considerable escalation in the prices of Nifty, Energy Index started treading the downward path. Visual inspection of these graphs provides us a primary indication that different asset classes might be linked differently across different states of the economy.

Returns of all the above-mentioned price series are calculated by taking the first differences of the logarithm of the two successive prices i.e. $r_{t}=\log \left(P_{t} / P_{t-1}\right)$. Table 1 represents the descriptive statistics of return series of all asset classes. Summary statistics suggest that Nifty had the highest mean average daily returns followed by Metal and G-sec index. Energy has the lowest mean average daily returns. However , during the entire time frame the maximum daily average return was shown by Nifty followed by Agriculture and Energy. In terms of volatility Energy displays the highest volatility followed by Nifty and Metal. 
Figure 1. Daily Price Movements for Each of the Five Assets

AGRI

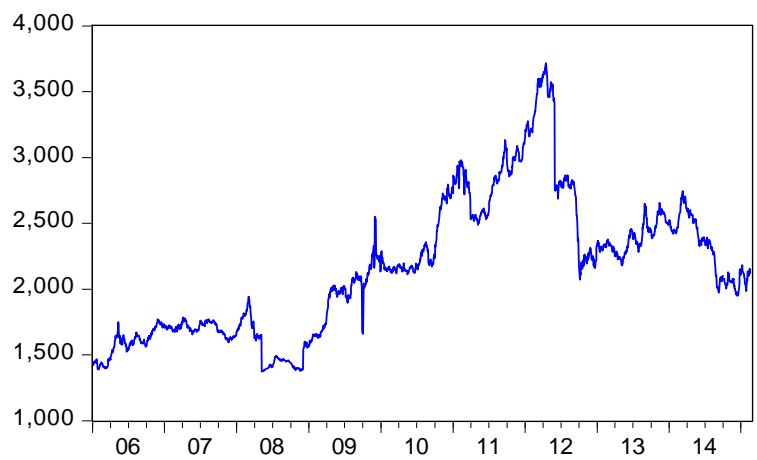

GSEC

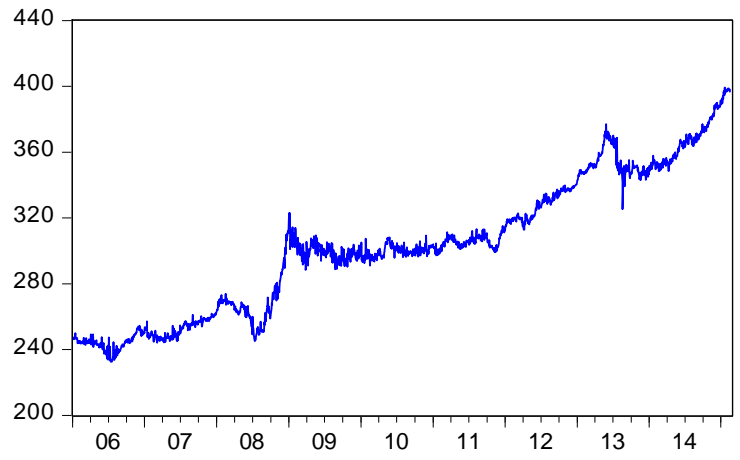

NIFTY

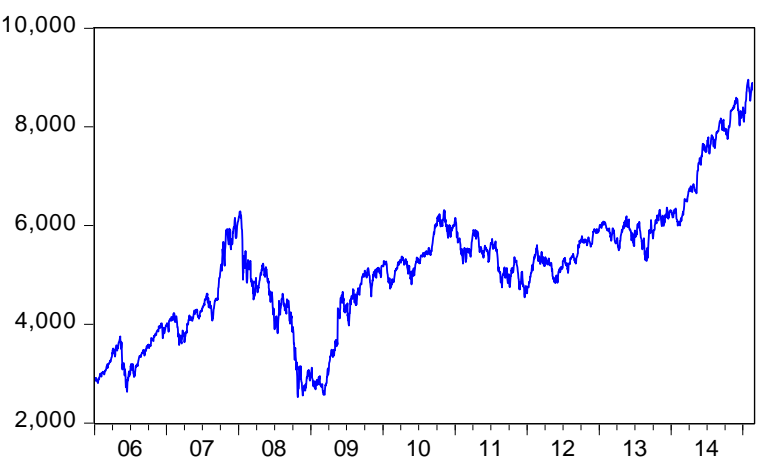

ENERGY

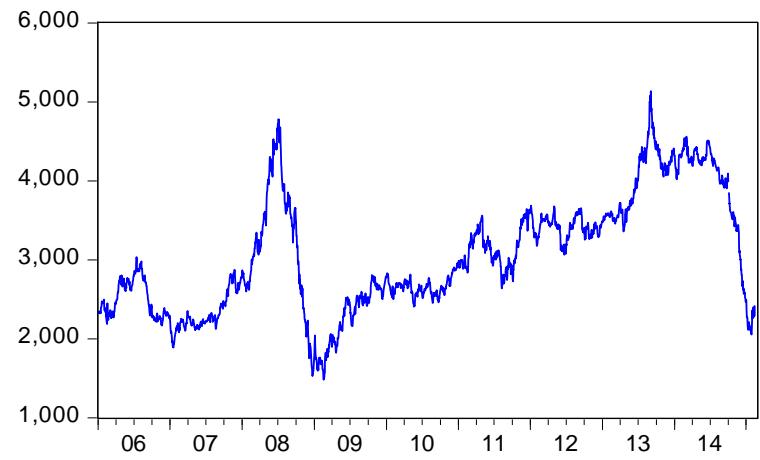

METAL

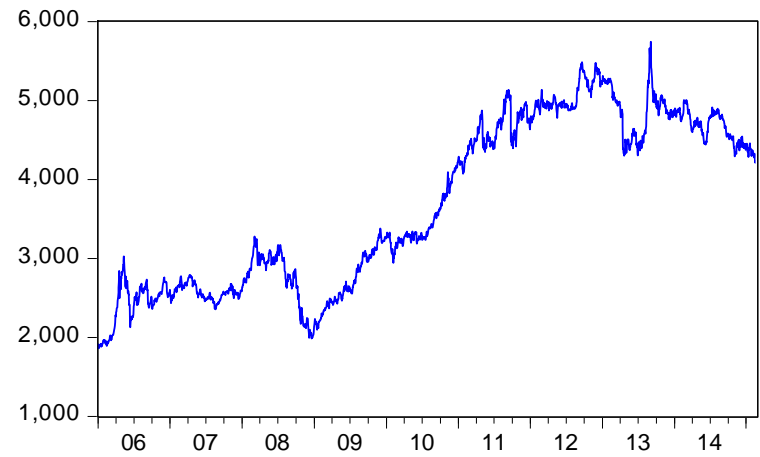

G-sec index exhibits the lowest volatility. In a nutshell, Nifty had high returns and high volatility whereas Energy had low returns and highest volatility; G-sec gave moderate returns with lowest volatility. Returns of all the series were negatively skewed and the kurtosis is much higher than 3 for all the cases. This indicates the deviation of the series from the normal distribution which was then confirmed by the JarqueBera statistics. JB statistics showed that all the series were not normally distributed. Further, the order of integration of the data series was tested by using Augmented Dickey-Fuller (ADF) unit root test. The null hypothesis of unit root was accepted for all the series at the price levels while it was rejected for all the return series. This indicates that all the series were integrated of the order one. Table 2 presents the Pearson correlation between various asset class and respective t-statistic by assuming the static economic state. Contrary to the expectations, returns of all the commodity indices were positively correlated with Nifty index and negatively correlated with the G-sec index. Energy index showed the highest positive correlation of around $12 \%$ and Agriculture index showed the lowest correlation of around $3 \%$ with the equity index. Only Nifty Index demonstrated a positive correlation with G-sec Index while all the commodity indices were 
negatively correlated, but they were found to be insignificant. Amongst the commodity indices, Metal and Energy possess the highest correlation of nearly $43 \%$ which is highly significant corroborated by the t-statistic. The high correlation between Nifty and Energy index can be explained by the fact that movement of crude oil is expected to have a significant impact on the stock markets through various macroeconomic channels like interest rate, exchange rate, inflation etc. Agricultural market in India moves quite independent of the stock market due to the involvement of physical assets and factors like carrying cost, seasonal pattern, shelf life, transportation cost, hence they are expected to possess low correlation and move independently.

Table 2. Pearson Correlation Coefficients Between Pairs of Asset Classes

\begin{tabular}{crrrrr}
\hline $\begin{array}{l}\text { Correlation } \\
\text { t-Statistic }\end{array}$ & DLA & DLE & DLG & DLM & DLN \\
\hline DLA & 1.000000 & & & & \\
& ---- & & & & \\
DLE & 0.065954 & 1.000000 & & & \\
& $3.227329^{*}$ & ---- & & & \\
DLG & -0.036019 & -0.009831 & 1.000000 & & \\
& -1.759806 & -0.480027 & ---- & & \\
DLM & & & & & \\
& 0.065551 & 0.433843 & -0.002915 & 1.000000 & \\
& $3.207525^{*}$ & $23.51076^{*}$ & -0.142310 & ---- & \\
DLN & & & & & \\
& 0.029527 & 0.126519 & 0.064713 & 0.050093 & 1.000000 \\
\hline
\end{tabular}

Notes: The sample period ranges from Jan 2006 to Dec 2014. Ordinary Pearson correlation method is used for calculating $t$-statistics which are mentioned in italics. * denotes rejection of hypothesis at 5\% level.

\section{Empirical Analysis}

Table 3 lists the parameter estimates of two state Markov regime switching models with p-value associated with each parameter in parenthesis. It also reports the ergodic probability and duration of the system in each regime. In the present study, returns were modelled as AR (1) process with regime switching in both mean and variances. From the output it is evident that the regime switching model bifurcates the returns and volatility behaviour of returns of the asset class under consideration into two distinct regimesone with positive mean returns $(0.036,0.06,0.02,0.09$ and 0.10$)$ and other with negative mean returns ($0.39,-0.21,-0.01,-0.24,-0.10)$. Also, it is apparent that regime with positive mean return has lower standard deviation (log sigma value) in all the asset classes as compared to volatility in negative mean return regime. Therefore , we specify "Regime 1" as the Negative Return and High Volatility or "Crisis" regime and "Regime 2 " as the Positive Return and Low volatility or "Tranquil" regime. Further, high values of ergodic probabilities suggest that both these states are highly stable and once the returns enter into one state they tends to remain in the same state. However, in context of Agriculture markets tranquil regime is more stable (transition probability to same state 0.98) than crises regime (transition probability to same state 0.42) whereas for equity markets both the regimes are near equally stable with ergodic probabilities of 0.97 and 0.98 respectively. On the same lines the duration of Tranquil state is higher in all the cases with maximum of 88 days for Nifty, followed by 48 days in Agri and average of around 30 days in Energy, G-sec and Metal indices respectively. Crisis regime tends to be of shorter durations with highest being 35 days for Nifty and spiralling down to just 2 days, the least, for Agriculture index. The possible explanation for such low duration of crises regime in Agriculture market is that during crises generally food inflation increases which leads to rise in the prices of Agriculture commodities and they move out of the crises regime. 
Figure 2 provides the smoothed probability diagram of equity, g-sec and three commodity market returns in tranquil regimes. As these diagrams are mirror images of each other in two regimes, therefore in the figure only smoothed probabilities of tranquil regime are presented.

Table 3. Parameters of Markov Regime Switching Model

\begin{tabular}{lcrrrr}
\hline Parameter & Agriculture & Energy & $\begin{array}{r}\text { Government } \\
\text { securities }\end{array}$ & Metal & Nifty \\
\hline $\boldsymbol{\Phi}$ & 0.028 & 0.077603 & -0.34289 & -0.01171 & 0.089525 \\
& $(0.0649)$ & $(0.0003)^{*}$ & $(0.000)^{*}$ & $(0.2481)$ & $(0.0000)^{*}$ \\
$\boldsymbol{\mu}_{\mathbf{0}}$ & -0.003909 & -0.00219 & -0.00011 & -0.00246 & -0.00107 \\
& $(0.7624)$ & $(0.1771)$ & $(0.3456)$ & $(0.0298)^{*}$ & $(0.3692)$ \\
$\boldsymbol{\mu}_{\mathbf{1}}$ & 0.000361 & 0.000643 & 0.000286 & 0.000925 & 0.001075 \\
& $(0.0224)^{*}$ & $(0.0781)^{* *}$ & $(0.0007)^{*}$ & $(0.0000)^{*}$ & $(0.0000)^{*}$ \\
Log $\boldsymbol{\sigma}_{\mathbf{0}}$ & -2.922852 & -3.60758 & -4.31487 & -3.74405 & -3.70548 \\
Log $\boldsymbol{\sigma}_{\mathbf{1}}$ & -4.956503 & -4.47135 & -5.41694 & -4.81 & -4.68601 \\
$\mathbf{P}\left[\mathbf{S}_{\mathbf{t}}=\mathbf{0}\right]$ & 0.418748 & 0.88546 & 0.859407 & 0.859407 & 0.971519 \\
$\mathbf{P}\left[\mathbf{S}_{\mathbf{t}}=\mathbf{1}\right]$ & 0.979169 & 0.965605 & 0.970204 & 0.970204 & 0.988667 \\
$\mathbf{S t}=\mathbf{0}$ & 1.720426 & 8.730564 & 12.61628 & 7.112723 & 35.11093 \\
$\mathbf{S t}=\mathbf{1}$ & 48.00536 & 29.07437 & 31.65505 & 33.56126 & 88.23798 \\
AIC & -6.780875 & -5.56307 & -7.19308 & -6.25138 & -5.879 \\
HQ & -6.774704 & -5.5569 & -7.18691 & -6.24521 & -5.87283 \\
SIC & -6.763919 & -5.54612 & -7.17612 & -6.23443 & -5.86205 \\
Log Likelihood & 8093.193 & 6640.962 & 8584.745 & 7461.772 & 7017.71 \\
\hline
\end{tabular}

Notes: The sample period ranges from the Jan 2006 to Dec 2014. P-values have been mentioned in parentheses. * denotes rejection of null hypothesis at $5 \%$ level. ${ }^{* *}$ denotes rejection of null hypothesis at $10 \%$ level.

These figures display visually the persistence of high return and low volatility regime and also capture the timing of shift from tranquil regime to crises regime. Smoothed probability diagram of Nifty indicates that high return regime is very persistent and it tends to remain in regime most of the time. However, from 2008 to 2009 negative return regime was prevalent, which is justified due to the onset of financial crisis at the global level. The results of smoothed probability for Nifty are in line with the macro-economic events happening in Indian economy due to which regime shift in returns of Nifty occurs. Probability diagram of Tranquil regime for metal indicates that during 2006 metals were in low returns regime for a very short span followed by high return regime till 2008. During 2008, Metal Index again reverts to the crisis regime and eventually begins to recover thereby shifting to high return and low volatility regime. G-Sec index also reveals the high persistence of tranquil regime interrupted by the crises regime for a short span of time during 2008. This contagion effect in various asset classes during crises regime can be explained by the onset of global crises due to which there is herding behaviour among the investors which in turn push the market into in to bearish phase. Contrary to the above, smoothed probability diagrams of Agriculture and Energy reveals that these two commodities keeps on swinging form one regime to another regime quite frequently. These results for Energy index can be explained based on the fact that crude oil constitutes the major proportion of Energy index and the movement of crude oil prices is determined on the basis of various global macroeconomic factors and the chance of these global factors to swing is higher as compared to the domestic factors. 
Figure 2. Smoothed Probability Diagrams for All the Asset Classes in Tranquil Regime
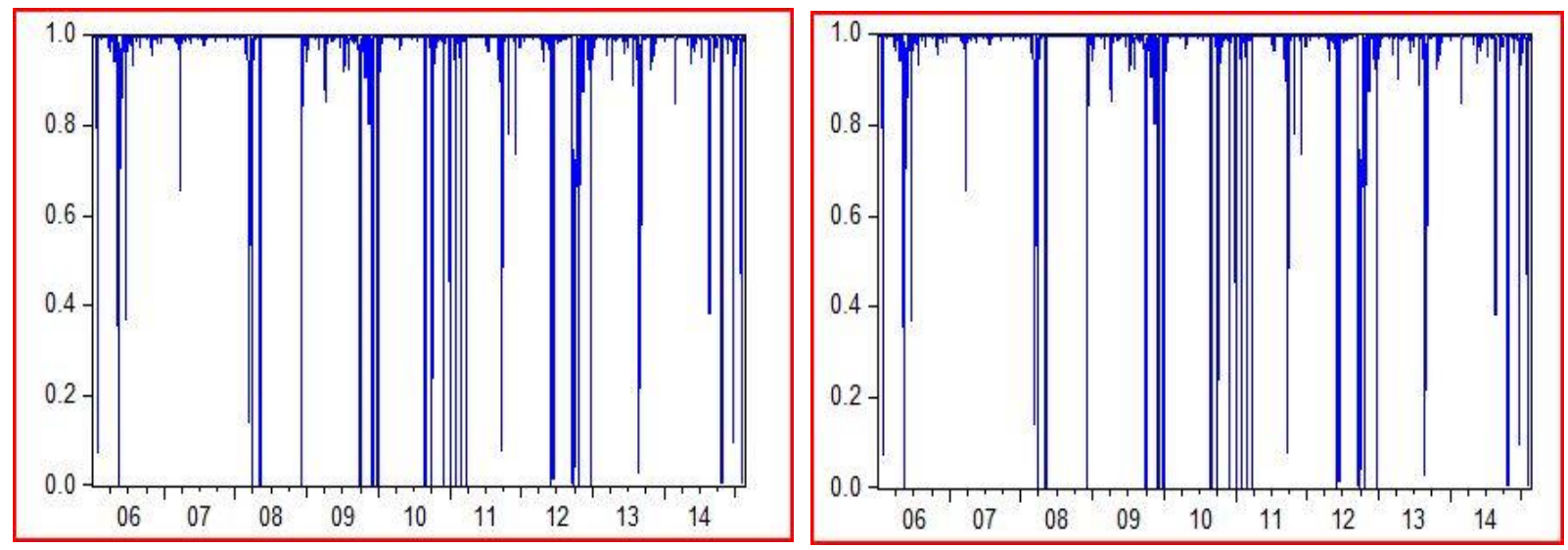

Energy
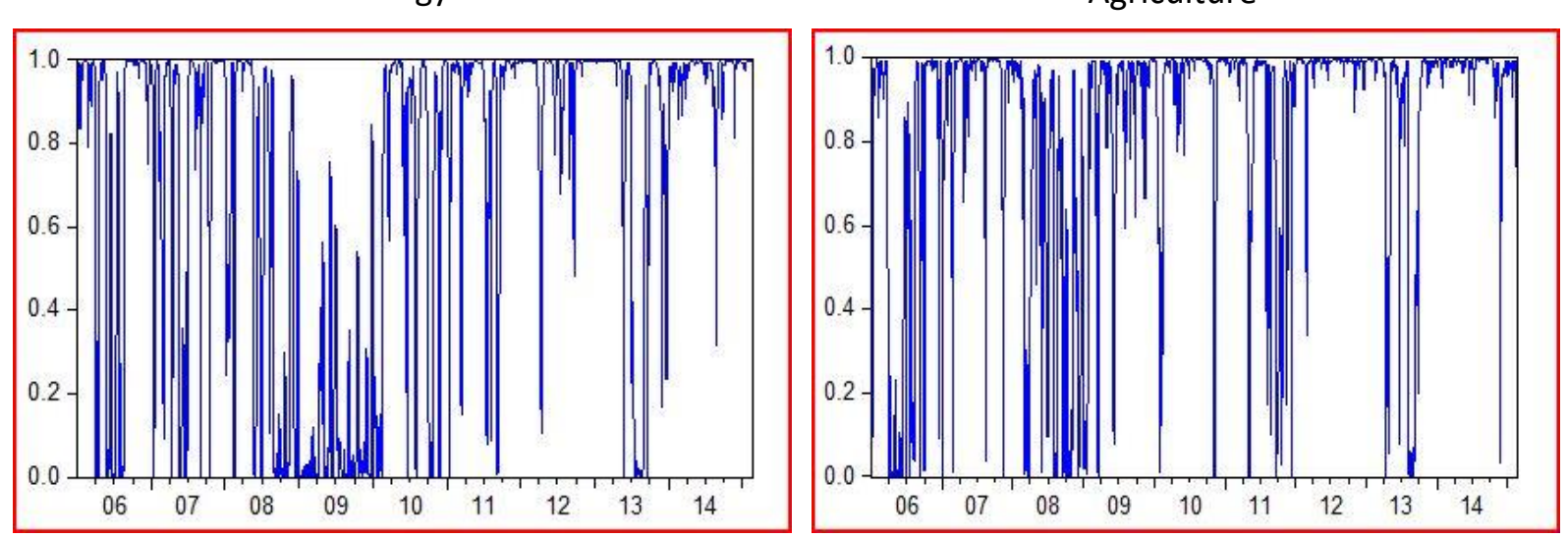

G-Sec

Metal

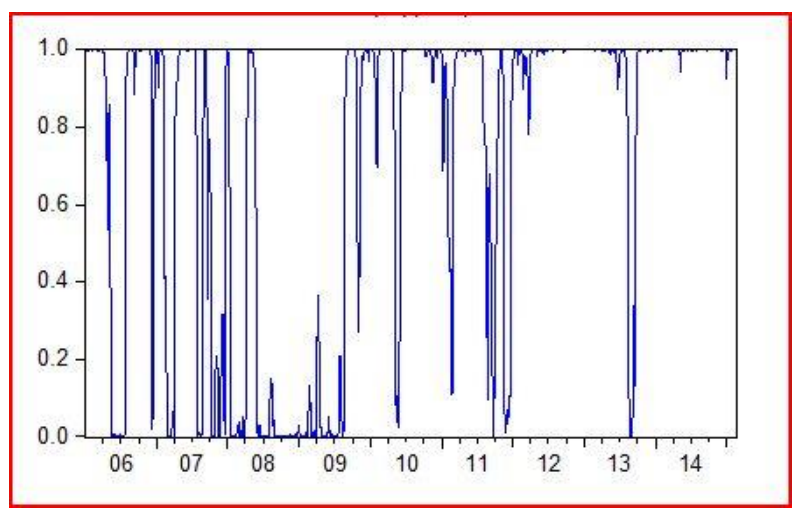

Nifty

The justification for the rapid movement of Agriculture index from one regime to another is that most of the agricultural commodities are seasonal that exhibit cyclical pattern of sowing and harvesting within a year and provide higher returns (tranquil regime) during sowing season which falls significantly during harvesting season (supply rises vis-a-vis demand) thereby entering into low return regime. Prevalent weather conditions like the recent El-Nino affect the rainfall in the geography thereby directly impacting agricultural produce which in turn impacts the Agriculture index (Domino effect). Thus, it can be seen that Agriculture index is susceptible to volatilities of various types resulting in a frequent regime switching behaviour.

Table 4 show the data concerning correlations between pairs of assets classes under investigation. The first half of the table corresponds to correlations between assets classes in the Crisis regime while the 
second half corresponds to the correlations between asset classes in the Tranquil regime. If observed keenly, it is interesting to note that the correlations between a pair of asset classes do not hold the same relationship in both the regimes. Consider the pair of Nifty and G-sec indices which have a positive correlation 0.0546 in Tranquil regime which almost ceases to exist at 0.003 in Crisis regime. A similar contrast is brought forward by the pair of G-sec and Agriculture indices which have a visibly negative correlation -0.018 in the Crisis regime which tends to $0-$ (tends to zero from negative side) in the Tranquil regime. These observations provide key inputs for portfolio managers and investors to design their portfolio under varied economic conditions. While a negative correlation between G-sec and Agriculture indices can be exploited for hedging under turbulent circumstances these might not help hedge in Tranquil conditions. The tables help us to draw even more interesting parallels. In the first table, Crisis regime, the highest correlation is exhibited by Metal and Energy indices with a value of 0.280 while in the tranquil regime the correlation rises to 0.320 for the pair. This shows that Metal and Energy indices are more positively correlated in the tranquil regime. Thus, it can be deduced that a pair of asset classes may exhibit different levels of correlations under different economic scenarios and might not necessarily assume a static or linear relationship at all points in time. It is, therefore, imperative for portfolio managers to clearly understand the dynamics of the economy and take into consideration time varying correlations between asset classes while designing their portfolios.

Table 4. Pearson Correlation Between Pairs of Asset Classes in Regime 1 and Regime 2

\begin{tabular}{|c|c|c|c|c|c|}
\hline \multicolumn{6}{|c|}{ REGIME 1} \\
\hline & RAG1 & RE1 & RGS1 & RM1 & RN1 \\
\hline \multirow[t]{2}{*}{ RAG1 } & 1.000000 & & & & \\
\hline & ---- & & & & \\
\hline \multirow[t]{2}{*}{ RE1 } & 0.024299 & 1.000000 & & & \\
\hline & 1.186781 & ---- & & & \\
\hline \multirow[t]{2}{*}{ RGS1 } & -0.018027 & -0.031087 & 1.000000 & & \\
\hline & -0.880331 & -1.518606 & ----- & & \\
\hline \multirow[t]{2}{*}{ RM1 } & 0.015502 & 0.280150 & -0.002113 & 1.000000 & \\
\hline & 0.756993 & $14.24926^{*}$ & -0.103187 & ----- & \\
\hline \multirow[t]{2}{*}{ RN1 } & 0.025200 & 0.037819 & 0.003713 & 0.022175 & 1.000000 \\
\hline & 1.230825 & 1.847881 & 0.181308 & 1.082977 & ---- \\
\hline \multicolumn{6}{|c|}{ REGIME 2} \\
\hline \multirow{3}{*}{ RA2 } & RA2 & RE2 & RG2 & RM2 & RN2 \\
\hline & 1.000000 & & & & \\
\hline & ---- & & & & \\
\hline \multirow[t]{2}{*}{ RE2 } & 0.077409 & 1.000000 & & & \\
\hline & $3.790952 *$ & ----- & & & \\
\hline \multirow[t]{2}{*}{ RG2 } & $-2.22 \mathrm{E}-05$ & -0.032800 & 1.000000 & & \\
\hline & -0.001083 & -1.602384 & ----- & & \\
\hline \multirow[t]{2}{*}{ RM2 } & 0.079932 & 0.320235 & -0.007316 & 1.000000 & \\
\hline & $3.915283^{*}$ & $16.50505^{*}$ & -0.357198 & ---- & \\
\hline \multirow[t]{2}{*}{ RN2 } & 0.019108 & 0.117034 & 0.054665 & 0.030719 & 1.000000 \\
\hline & 0.933155 & $5.753875^{*}$ & 2.673093* & 1.500622 & ---- \\
\hline
\end{tabular}

Notes: The sample period ranges from Jan 2006 to Dec 2014. Ordinary Pearson correlation method is used for calculating t-statistics which are mentioned in italics. * denotes rejection of hypothesis at $5 \%$ level. 


\section{Conclusion}

This paper empirically examines the interrelationships between commodity futures (Energy, Metal and Agriculture) and stock markets in dynamic economic states by employing Markov Regime Switching model proposed by Kin (1999) which has the capability of capturing temporal asymmetries and nonlinear dynamics of error terms in addition to mean returns. The major advantage of Regime Switching model is that it does not necessitate the explicit specification of the time when the shift in economic states occurs. It utilizes the supplied data to detect the switching point in the volatility states of the returns, calculates the transition probability of moving from one state to another state and measures the lengths of duration in each state. In order to provide robust results this paper uses daily data from 2006 to 2014 which significantly represents different states in the Indian Economy. The result of the study confirms the impact of economic environment on Indian commodity and stock markets and validates the presence of two distinct regimes: a "tranquil regime" representing the state of positive return and low volatility and a "crisis regime" representing the state of negative return and high volatility. The findings are in tune with the findings reported in the title "Asset Market Linkages" (Chan, Brooks, Gray 2009). Both the regimes are highly stable except for agriculture for which the probability to stay in crisis regime is least. Duration of tranquil regimes is higher than crises regime in all asset classes. Nifty stays for highest duration in both the regimes being 88 days in tranquil regime and 36 days in crises regime. This further indicates that the equity markets are more stable and investors gets sufficient time to play within each regime. Agriculture tends to remain for only 2 days in crises regime. Smoothed probability graph indicates that equity, metal and g-sec index remain in tranquil regime and switch to crises regime only during 2008 crisis, however agriculture and energy indices oscillate between the two regimes more frequently. Once the switching points were detected, the interrelationship among various asset markets has been examined. Result of the study indicates different asset classes may exhibit different levels of correlations under different economic scenarios and might not necessarily assume a static or linear relationship at all points in time. In a portfolio when commodity futures are combined with stock, due consideration must be given to the state varying behaviour of different asset class and the findings of the study will be useful for portfolio managers and investors to clearly understand the dynamics of the economy and provide them key inputs to design their portfolio under varied economic conditions.

\section{References}

Aggarwal, N., Jain, S., \& Thomas, S. (2014). Do futures markets help in price discovery and risk management for commodities in India? (No. 2014-020). Indira Gandhi Institute of Development Research, Mumbai, India.

Ahuja, N. L. (2006). Commodity derivatives market in India: Development, regulation and future prospects. International Research Journal of Finance and Economics, 2(1), 153-162.

Anson, M. J. (1999). Maximizing utility with commodity futures diversification. The Journal of Portfolio Management, 25(4), 86-94.

Bhar, R., \& Hammoudeh, S. (2011). Commodities and financial variables: Analyzing relationships in a changing regime environment. International Review of Economics \& Finance, 20(4), 469-484.

Bodie $Z$, 1983). Commodity Futures as a Hedge against Inflation. The Journal of Portfolio Management, Spring, pp. 1217.

Bodie Z and Rosansky V ,1980). Risk and Returns in Commodity Futures. Financial Analysts Journal, May-June, pp. 2739.

Bose, S. ,2008). Commodity Futures Market in India: A Study of Trends in the Notional Multi-Commodity Indices. Money \& Finance, 3,3), 125-158.

Bose, S. ,2009). The role of Futures market in aggravating commodity price inflation and the future of Commodity Futures in India. Money and Finance, 4,1), 1-28.

Boyarchenko, S., \& Levendorskiĭ, S. (2008). Exit problems in regime-switching models. Journal of Mathematical Economics, 44(2), 180-206. 
Chan, K. F., Treepongkaruna, S., Brooks, R., \& Gray, S. (2011). Asset market linkages: Evidence from financial, commodity and real estate assets. Journal of Banking \& Finance, 35(6), 1415-1426.

Chang, K. L. (2012). Volatility regimes, asymmetric basis effects and forecasting performance: An empirical investigation of the WTI crude oil futures market. Energy Economics, 34(1), 294-306.

Charlot, P., \& Marimoutou, V. (2014). On the relationship between the prices of oil and the precious metals: Revisiting with a multivariate regime-switching decision tree. Energy Economics, 44, 456-467.

Chen, S. S. (2010). Do higher oil prices push the stock market into bear territory?. Energy Economics, 32(2), $490-495$.

Cheung, C. Sherman; Miu, Peter ,2010). Diversification Benefits of Commodity Futures. Journal of International Financial Markets, Institutions \& Money, Vol. 20 Issue 5, p451-474. 24p

Chevallier, J. (2012). Global imbalances, cross-market linkages, and the financial crisis: A multivariate Markov-switching analysis. Economic Modelling,29(3), 943-973.

Choi, K., \& Hammoudeh, S. ,2010). Volatility behavior of oil, industrial commodity and stock markets in a regimeswitching environment. Energy Policy, 38,8), 4388-4399.

Conover, C. M., Jensen, G. R., Johnson, R. R., \& Mercer, J. M. (2009). Can precious metals make your portfolio shine?. Journal of Investing, 18(1), 75-86.

Delatte, A. L., \& Lopez, C. ,2013). Commodity and equity markets: Some stylized facts from a copula approach. Journal of Banking \& Finance, 37,12), 5346-5356.

Edwards F and Park J 1996). Do Managed Futures Make Good Investments? Journal of Futures Markets, Vol. 16, pp. 475-517.

Fong, W. M., \& See, K. H. (2002). A Markov switching model of the conditional volatility of crude oil futures prices. Energy Economics, 24(1), 71-95.

Gargano, A., Pettenuzzo, D., \& Timmermann, A. G. (2014). Bond return predictability: Economic value and links to the macroeconomy. Available at SSRN 2471273.

Greer R J 1978). Methods for Institutional Investment in Commodity Futures. The Journal of Derivatives, Winter, pp. 2836.

Gorton, G. B. and Rouwenhorst ,2006). Facts and Fantasies about Commodity Futures. Financial Analysts Journal, 62,2), 47-68.

Gorton, G. B., Hayashi, F., \& Rouwenhorst, K. G. (2007). The fundamentals of commodity futures returns (No. w13249). National Bureau of Economic Research.

Gupta, K., \& Singh, B. (2007, April). An examination of price discovery and hedging efficiency of indian equity futures market. In 10th Indian Institute of Capital Markets Conference Paper.

Halpern P and Warsager R ,1998). The Performance of Energy and Non Energy Based Commodity Investment Vehicles in Periods of Inflation. The Journal of Alternative Investments, Summer, pp. 75-81.

Hamilton, J. D. (1989). A new approach to the economic analysis of nonstationary time series and the business cycle. Econometrica: Journal of the Econometric Society, 357-384.

Hammoudeh, S., Nguyen, D. K., Reboredo, J. C., \& Wen, X. (2014). Dependence of stock and commodity futures markets in China: Implications for portfolio investment. Emerging Markets Review, 21, 183-200.

Huang, J. Z., \& Zhong, Z. K. (2013). Time variation in diversification benefits of commodity, REITs, and TIPS. The Journal of Real Estate Finance and Economics, 46(1), 152-192.

Jarecki, H. G. (2007). Commodities create the right mix. FUTURES-CEDAR FALLS IOWA THEN CHICAGO-, $36(3), 66$.

Jalil, N. A., Ghani G. M., Daud J., and Ibrahim M. ,2009). Stock Price Movements: Does Change in Energy Price Matter? Instituto Brasileiro de Estudos Empresariais e Jurídicos ,(BEJ), 2,1).

Jensen, G., Johnson, R.R.and Mercer, J.M. (2000). Efficient use of commodity futures in diversified portfolios. The Journal of Futures Markets, vol. 20 no 5, pp. 489-506.

Jensen G, Johnson R and Mercer J. (2002). Tactical Asset Allocation and Commodity Futures. Journal of Portfolio Management, Summer, pp. 100-111.

Jensen $\mathrm{G}$ et al. (2010). Is Now the time to add Commodities to your Portfolio. Journal of Investing. Vol. 19 Issue 3, p1019. $10 p$

Ji, Q., \& Fan, Y. (2012). How does oil price volatility affect non-energy commodity markets?. Applied Energy, 89(1), 273280. 
Kiran, K. (2006). A Study of Castorseed Futures Market in India (Doctoral dissertation, Ph. D Thesis submitted to Indira Gandhi Institute of Development Research, Mumbai, India, retrieved from http://papers. ssrn. com/sol3/papers. $\mathrm{cfm})$.

Kumar, B., Singh, P., \& Pandey, A. (2008). Hedging effectiveness of constant and time varying hedge ratio in Indian stock and commodity futures markets.Available at SSRN 1206555.

Kumar, B. (2009). Effect of Futures Trading on Spot Market Volatility: Evidence from Indian Commodity Derivatives Markets. Available at SSRN 1364231.

Kumar, B., \& Pandey, A. (2009, August). Role of Indian Commodity Derivatives Market in Hedging Price Risk: Estimation of Constant and Dynamic Hedge Ratio and Hedging Effectiveness. In 22nd Australasian Finance and Banking Conference.

Lee, C. F., \& Leuthold, R. M. (1986). 5 An Analysis Of Investment Horizon And Alternative Risk-Return Measures For Commodity Futures Markets. Futures Markets: Their Establishment and Performance, 119-36.

Lin, B., \& Wesseh, P. K. (2013). What causes price volatility and regime shifts in the natural gas market. Energy, 55, 553563.

Levy, M., \& Kaplanski, G. ,2015). Portfolio selection in a two-regime world. European Journal of Operational Research, 242,2), 514-524.

Lee, H. T. (2010). Regime switching correlation hedging. Journal of Banking \& Finance, 34(11), 2728-2741.

Li, S. F., Zhu, H. M., \& Yu, K. (2012). Oil prices and stock market in China: A sector analysis using panel cointegration with multiple breaks. Energy Economics, 34(6), 1951-1958.

Mensi, W., Beljid, M., Boubaker, A., \& Managi, S. (2013). Correlations and volatility spillovers across commodity and stock markets: Linking energies, food, and gold. Economic Modelling, 32, 15-22.

Mishra, A. K. (2008, January). Commodity Futures Markets in India: Riding the Growth Phase. In International Conference on Commodity Future: Riding the Growth Phase.

McCown, J. R., \& Zimmerman, J. R. (2006). Is gold a zero-beta asset? Analysis of the investment potential of precious metals. Analysis of the Investment Potential of Precious Metals (July 24, 2006).

Nath, G. C., \& Lingareddy, T. ,2008). Impact of Futures Trading on Commodity Prices. Economic and Political Weekly, 1823

Nomikos, Nikos K., and Panos K. Pouliasis. ,2011). Forecasting petroleum futures markets volatility: The role of regimes and market conditions." Energy Economics 33 ,2) 321-337.

Park, J. W. and Ratti, R.A.,2008). Oil Price Shocks and Stock Markets in the medals and 13 European Countries. Energy Economics, 30,5), 2587-2608.

Sahi, G. S., \& Raizada, G. (2006). Commodity Futures Market Efficiency in India and Effect on Inflation. Available at SSRN 949161.

Schneeweis, T., \& Spurgin, R. (2000). Hedge Funds: Portfolio risk diversifiers, return enhancers or both. CISDM/Isenberg School of Management, University of Massachusetts

Shalini, V., \& Prasanna, K. (2015). Impact of the financial crisis on Indian commodity markets: Structural breaks and volatility dynamics. Energy Economics.

Srinivasan, P. (2012). Price discovery and volatility spillovers in Indian spot-futures commodity market. The IUP Journal of Behavioral Finance, 9(1), 70-85.

Thuraisamy, K. S., Sharma, S. S., \& Ahmed, H. J. A. (2013). The relationship between Asian equity and commodity futures markets. Journal of Asian Economics, 28, 67-75.

Vo, M. T. (2009). Regime-switching stochastic volatility: evidence from the crude oil market. Energy Economics, 31(5), 779-788.

Wang, M. L., Wang, C. P. and Huang, T. Y.,2010). Relationships among Oil Price, Gold Price, Exchange Rate and International Stock Markets. International Research Journal of Finance and Economics, 47, 82-91

Yaganti, C. H., \& Kamaiah, B. (2012). Hedging Efficiency of Commodity Futures Markets in India. IUP Journal of Financial Risk Management, 9(2), 40. 
This Page Intentionally Left Blank 